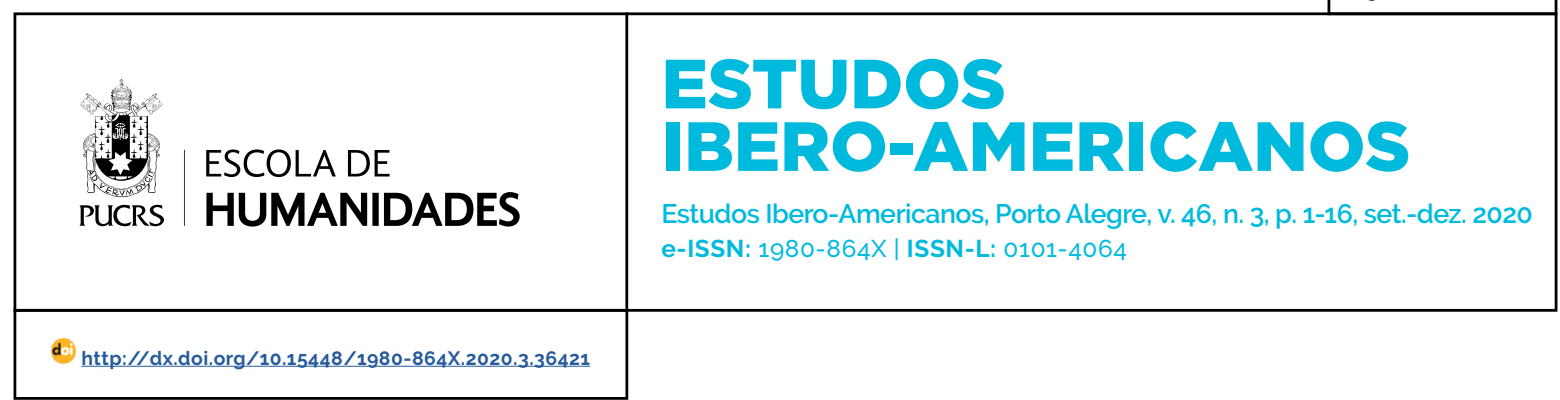

DOSSIÊ

\title{
El Código de Paz y la trama del panamericanismo en la década de 1930
}

\author{
O Código da Paz e a trama do pan-americanismo na década de 1930
}

The Peace Code and the plot of Pan Americanism in the $1930 \mathrm{~s}$

\section{Alexandra Pita \\ González ${ }^{1}$ \\ orcid.org/0000-0003-1211-0365 \\ capitag@ucol.mx}

Recebido em: 6 jan. 2020. Aprovado em: 16 maio 2020 Publicado em: 21 dez. 2020.

\section{(c) (1)}

Artigo está licenciado sob forma de uma licença Creative Commons Atribuição 4.0 Internacional.
Resumen: El Código de la Paz fue una propuesta de la diplomacia mexicana para construir un instrumento jurídico capaz de aglutinar los tratados y acuerdos anteriores y dotarlo de mayor efectividad al crear una serie de instancias permanentes para intervenir en caso de conflictos en el continente. Como pretende mostrar este artículo a través de la documentación de Alfonso Reyes, su origen y desarrollo durante la década de 1930 estuvo relacionado con la decisión de convertir a México en un hábil negociador de las Conferencias Panamericanas. Así, a través de un caso de estudio poco analizado hasta ahora, se puede observar el papel de México en la triangulación entre los deseos hegemónicos de Estados Unidos y Argentina. Con ello se pretende afianzar las interpretaciones que analizan el panamericanismo como una trama compleja de negociaciones múltiples, desmitificando la idea de que fue un escenario donde los paises latinoamericanos tuvieron poca influencia y escasa capacidad de negociación. Palabras clave: derecho internacional americano, México, Alfonso Reyes

Resumo: O Código da Paz era una proposta da diplomacia mexicana para a construção de um instrumento legal capaz de aglutinar os tratados e acordos anteriores e proporcionar maior efetividade, criando instâncias permanentes para intervir em caso de conflitos no pais o continente. Como este artigo pretende mostrar através da documentação de Alfonso Reyes, sua origem e desenvolvimento durante la década da 1930 estavam relacionados à decisão de transformar o México em um negociador qualificado das Conferências Pan-Americanas. Assim, através de um estúdio de caso pouco analisado até o momento, pode-se observar o papel do México na triangulação entre os desejos hegemônicos dos Estados Unidos e da Argentina. Pretende-se fortalecer as interpretações que analisam o pan-americanismo como um enredo complexo de múltiplas negociações, desmitificando a ideia de que era um cenário em que os países latino-americanos tiveram pouca influência e baixa capacidade de negociação Palavras-chave: Direito Internacional Americano, México, Alfonso Reyes

Abstract: The Peace Code was a proposal by Mexican diplomacy, especially Alfonso Reyes, to build a legal instrument capable of agglutinating the previous treaties and agreements and providing it with greater effectiveness by creating permanent instances to intervene in case of conflicts in the continent. As this article intends to show through the documentation of Alfonso Reyes, its origin and development during the 1930s was related to the decision to turn Mexico into a skilled negotiator of the Pan American Conferences. Thus, through a case study little analyzed so far, the role of Mexico in the triangulation between the hegemonic desires of the United States and Argentina can be observed. This is intended to strengthen the interpretations that analyze Pan-Americanism as a complex plot of multiple negotiations, demystifying the idea that it was a scenario where Latin American countries had little influence and low negotiation capacity. Keywords: American International Law, Mexico, Alfonso Reyes. 


\section{Introducción}

Si bien las guerras entre los paises latinoamericanos no fueron numerosas, su impacto fue considerable durante la segunda mitad del siglo XIX y la primera del XX. ${ }^{2} \mathrm{~A}$ éstas debe agregarse otro tipo de conflictos entre naciones europeas y latinoamericanas que iniciaron desde la crisis del imperio español a inicios del siglo XIX y se mantuvieron hasta el bloqueo naval a Venezuela (1902-1903). Si bien la mayor parte de estas intervenciones militares eran puntuales otras intentaron reconquistar (España) o fundar un imperio (Francia). Además, hay que contar las sucesivas intervenciones militares que realizó Estados Unidos en la región. Para encontrar una respuesta jurídica a esto, desde el Congreso de Panamá -impulsado por Simón Bolivar- se inició una propuesta para codificar el Derecho Internacional, debate que continuó en las siguientes décadas, pero sólo con la participación de algunos paises latinoamericanos. ${ }^{3}$

Este debate tuvo un impulso mayor al iniciar las Conferencias Panamericanas (a finales del siglo XIX), donde se plantearon y discutieron las propuestas de derecho internacional realizadas por los abogados argentinos Carlos Calvo y Luis Maria Drago. Sus propuestas legales buscaron regular las reclamaciones por daños ocasionados contra sus bienes (o los de sus súbitos residentes en aquel país), así como por el cobro compulsivo de deudas de los paises latinoamericanos Ambos argumentos eran utilizados con frecuencia para justificar una intervención armada. ${ }^{4}$ Por su parte, Estados Unidos impulsó la construcción de un nuevo orden jurídico internacional americano tomando como modelo el sistema jurídico de su pais. Brown Scott y Agustín Álvarez fundaron el Instituto Americano de Derecho Internacional (1912), a través del cual circularon una serie de ideas sobre derecho internacional que se apartaban de la tradición europea basada en "el equilibrio de poderes" para defender la necesidad del arbitraje y asi resolver de manera pacifica los conflictos (Scarfi, 2014, pp. 50-57). 5

Como pretendo mostrar en este trabajo, el debate se intensificó en el ámbito de la Unión Panamericana durante la década de 1930 y en él, México tuvo una participación significativa a través de Alfonso Reyes, quien junto con otros diplomáticos elaboró y defendió el Código de la Paz. Con ello se rescatan dos aspectos poco conocidos. El primero, que hace a la trayectoria diplomática de Reyes, sobre el cual se ha estudiado principalmente por parcialidades (en su función como representante de México en distintos paises. Esta perspectiva se intensificó a partir de la publicación de sus diarios, donde quedaba manifiesto el peso que tuvo en su vida, apareciendo como un diplomático y no solo como un escritor. ${ }^{6}$

\footnotetext{
2 Entre las de mayor impacto se encuentran: la guerra de Triple Alianza que enfrentó a Argentina, Brasil y Uruguay contra Paraguay (864-1870), la del Pacífico que enfrentó a Chile contra Perú y Bolivia (1879-1884), y ya más cercana a nuestro período de estudio, el conflicto Leticia (entre Colombia y Perú entre 1932 y 1933) y la guerra del Chaco (entre Bolivia y Paraguay entre 1932 y 1935).

3 Las sucesivas Conferencias en Lima (1847, 1861 y 1867) siguieron con la propuesta, pero no fue sino hasta 1877-1878, que se realizó en esa ciudad un Congreso de Jurisconsultos Americanos con la participación de expertos de Argentina, Chile, Bolivia, Ecuador y Perú Los expertos elaboraron un Tratado (de Lima), pero éste no entro en vigor porque Perú no lo firmó. En 1889-90 en Montevideo se reunió un Congreso Jurídico Internacional participando Argentina, Chile, Bolivia, Brasil, Paraguay, Perú y Uruguay, quienes suscribieron varios tratados sobre aspectos internacionales (comercio, derecho penal, derecho procesal, propiedad literaria y artística, marcas de comercio y fábrica, ejercicio de profesiones liberales, aplicación de Leyes Extranjeras. Éstos fueron ratificados por varios Estados, pero su impacto directo fue la reunión de un Congreso Jurídico Centroamericano (1897-1901) en donde se suscribieron varios Convenios, en especial el del Asilo en Embajadas o Legaciones, que posteriormente tuvo influencia en el derecho continental. VILLALTA, 2012, pp. 1-2.

4 El delegado argentino Carlos Calvo estaba preocupado porque Estados Unidos se negó a firmar los derechos de extranjería en las primeras conferencias panamericanas (Washington, 1889-1890 y México 1901-1902), buscando que se consideraran las reclamaciones por vía diplomática. En respuesta, Calvo estableció que los extranjeros debian establecer sus reclamos, demandas y quedas en los tribunales locales y no en los internacionales, como medida para evitar las presiones diplomáticas o las intervenciones armadas. Influenciado por la doctrina Calvo, y en respuesta al bloqueo de países europeos a Venezuela en 1902 y a la negativa de Estados Unidos de aplicar la Doctrina Monroe (por considerar que sólo se aplicaba si el ataque pretendiera recuperar territorios americanos), el argentino Luis Maria Drago estableció en ese año que no se podía utilizar la fuerza para cobrar deudas (conocida como Doctrina Drago). TAMBURINI, 2002, pp. 84-86. 5 La perspectiva de Scott y Álvarez no fue la única que se incluyó en el Instituto, el cual durante la década de 1920 intentó equilibrar dos posturas distintas: aquellos que quienes querian implementar un derecho internacional como espacio multulateral y los que de manera más restrictirva querian supeditarlo al liderazo de Estados Unidos en el hemisferio. SCARFI, 2017, p. 89.

6 Los Diarios de Alfonso Reyes se compone de siete volúmenes, todos publicado por el FCE y prologados por diferentes autores, quienes escribieron estudios introductorios, notas, etc. Aparte, se publicó la compilación y selección en dos tomos de Víctor Díaz Arciniega (2001) sobre esta "misión diplomática" desarrollada entre 1920 y 1938 mostró a través de cartas e informes, telegramas y otros textos (ensayos, poemas) a Reyes como un especialista en cuestiones del servicio exterior
} 
Pese a esto, poco se ha estudiado a Reyes en relación con los organismos internacionales. ${ }^{7}$ Como se aborda en un trabajo anterior, el mexicano desde la década de 1920 y hasta 1942, fue un actor de gran relevancia para poner en marcha e impulsar numerosos proyectos de Cooperación Intelectual durante la entreguerra. En ese tipo de espacio multilateral es donde se logra entender tanto su profesionalización como diplomático como su capacidad de mediación entre su país, los demás de la región y los intereses europeos (Pita, 2014).

Menos conocida es la participación de Reyes en las Conferencias Panamericanas. Los estudios sobre panamericanismo suelen no prestar atención a este aspecto. Como excepción encontramos la tesis doctoral de Veremundo Carrillo (2018), quien ahace un estupendo análisis de la participación de México en la Unión Panamericana. Al hacerlo, recupera a Reyes, en especial al referirse al Código de la Paz, propuesta que valora por su originalidad, pero también por haber sido un medio de negociación significativo para la diplomacia mexicana en la compleja trama que tuvo a las conferencias como escenario de las tensiones regionales durante la década de 1930. Así, el presente trabajo complementa aquél no solo porque aborda el Código de la Paz de manera específica, sino porque incorporar información proveniente de otro tipo de fuente: la correspondencia (resguardada en la Capilla Alfonsina - CA) y el diario de Alfonso Reyes. Cabe aclarar que aunque tratemos sobre un Código, este no es un trabajo de historia del derecho internacional, el cual ha servido para comprender el contexto en el que se inserta y la dificultad en América Latina por encontrar un punto de acuerdo entre los actores que debatieron sobre el derecho internacional americano. ${ }^{8}$ Por último cabe mencionar que esta propuesta se dividió en dos grandes apartados correspondientes temporalmente con el primer y segundo intento por aprobar el Código de la Paz en las Conferencias Panamericanas de Montevideo (1933) y Buenos Aires (1936). A su vez, estos apartados están subdivididos, siguiendo las rutas (espaciales y temporales) que se siguieron.

\section{Primer intento (1933)}

a) Los preparativos. Santiago de Chile

El gobierno mexicano tenía grandes expectativas de la Conferencia Panamericana a realizarse en la ciudad de Montevideo en diciembre de 1933. No era para menos, dado su complicada historia con la Unión Panamericana. Durante las primeras Conferencias (hasta la de Buenos Aires de 1910) fue un interlocutor entre América Latina y EE. UU., y aunque bajo el régimen de Díaz se intentó evitar una confrontación directa se defendió la multilateralidad del panamericanismo al no aceptar el control absoluto del vecino del norte en el organismo. Tras la revolución se hicieron esfuerzos por romper el aislamiento del país a través de la diplomacia. Sin embargo, México no participó de la Conferencia de Santiago (1923) en protesta por el control de Estados Unidos sobre el organismo, por lo que no es de extrañar que convirtió la búsqueda de igualdad juridica en una causa. Entre 1927 y 1933 definió una "política hemisférica propia" asumiendo el liderazgo en iniciativas que buscaban consolidar el orden juridico entre los Estados americanos con el fin de equilibrar su política exteriory alcanzar el despegue económico. Este interés se vislumbró tanto en la intensificación de vínculos en el panamericanismo como en su diversificación al ingresar a la Sociedad de Naciones (CARRILLO, 2018, pp.394-395).

Por todo esto es comprensible que, meses antes del encuentro, la Secretaría haya preparado el terreno con la finalidad de asegurar el apoyo de otros gobiernos a sus propuestas. Para estos preparativos hubo dos personajes principales: Manuel Puig, quien acababa de asumir como Secretario de Relaciones Exteriores de México,

\footnotetext{
7 Entre las expeciones debemos mencionar el caso de Faián Herrea quien a través de varios trabajos a puesto de manifiesto la importancia de figuras como Alfonso Reyes, pero también Luis Sánchez Pontón, Isidro Fabela y Federico Bach (principlamente). Estas figuras han servido para explicar la compleja relación que tuvo México y la Sociedad de Naciones pero también para demostrar el éxito y la pericia de estos personajes al frente de numerosas proyectos y propuestas. Ver Herrera, 2009, 2013 y 2014.

8 La historia del derecho internacional es un área especializada que además ha tenido su propio camino. Para ver los cambios y tendencias de los útimos años remitimos a DOMINGUEZ; 2019, p 130-132.
} 
y Alfonso Reyes, embajador de México en Brasil, quien para ese entonces había acumulado una vasta experiencia tanto en los paises sudamericanos como en otras legaciones mexicanas en Europa. ${ }^{9}$ Además, Reyes tenía una perspectiva idónea para vislumbrar la relación entre la Unión Panamericana y la Sociedad de Naciones debido a su experiencia como representante de México en el Instituto Internacional de Cooperación Intelectual, organismo dependiente de la Sociedad de Naciones. ${ }^{10}$ Aunado a ello, desde Río, Reyes tenía informes directos de los primeros encuentros que realizaron los países involucrados en la solución de la Guerra del Chaco, sobre todo, de las acciones emprendidas principalmente por Argentina, país que disputaba el liderazgo en la pacificación de la contienda. ${ }^{11}$

En la primera comunicación entre Puig y Reyes, el Secretario le aclaró que se estaban preparando para el evento de Montevideo, pues éste sería de gran relevancia por el fracaso reciente de la Conferencia Económica Mundial de Londres, reunión en la cual México participó activamente por el interés de revalorizar la plata.12 Puig aseguró que la política mexicana en América Latina habia estado preparando "una atmósfera especialmente favorable para México, que nos promete una influencia legítima y útil en ella (la conferencia de Montevideo)". Por esto, le pide a Reyes que procure obtener de la cancillería brasileña infor- mación valiosa sobre la postura que tendrán en Montevideo sobre diversos temas de la agenda. Por su parte, le comunicará cuáles son las medidas que tomará México, para ver si es posible ponerse de acuerdo con el gobierno de Brasil, con el fin de tener "una acción lo más uniforme".13

Pocos días más tarde Reyes recibió instrucciones más precisas para abordar a personajes claves que pudieran asegurar el apoyo de Chile a México en la Conferencia. Para realizar estos encuentros pensaba que lo mejor sería trasladarse a Santiago de inmediato para permanecer ahi un mes y medio o dos, pero en carácter no oficial, por lo que debía encontrar una excusa (dar conferencias o cursos en la Universidad o motivos de salud). Estando en esa ciudad era indispensable que se contactara con el ministro de Relaciones Exteriores, Miguel Cruchaga, a quien consideraba "persona (de) alto relieve". La urgencia del traslado se debía a que el embajador mexicano en Chile, recientemente nombrado, Cienfuegos, no podría llegar a esa capital hasta dentro de dos o tres meses, lo cual impediria que se realizaran las "comunicaciones y contactos (que) necesitamos". Puig consideraba que Chile era un aliado fundamental, pues pensaba que habian sido ellos quienes estuvieron detrás del "asunto (del) Chaco" y no Brasil (y Estados Unidos a través de éste), como pensaba en Ginebra la Sociedad de Naciones. Reyes conservaria su cargo en Brasil y durante su estancia

\footnotetext{
9 Para ese año Reyes había acumulado una vasta experiencia en la diplomacia. Primero en la legación de España entre 1920 y 1924. luego en la de Francia entre 1925 y 1927 cuando fue trasladado a Buenos Aires entre 1927 y 1930 para pasar a la emabaja de Brasil desde 1930 y hasta 1936 que retornó a Buenos Aires para hacerse cargo de la embajada entre 1936 y 1937, regresando por último a Río por diez meses en 1938.

10 México ingresó recién a la Sociedad de Naciones en 1931 aduciendo que no había sido invitado en 1919 y una vez aclarado el malentendido, cuestionó la incorporación de la Doctrina Monroe dentro del Pacto de las Naciones. Pese a esto, se adhirió a Cooperación Intelectual desde 1926, gracias a las maniobras de Alfonso Reyes, en ese entonces en la legación de México en París, porque para ser miembro de Cooperación intelectual no era indispensable serlo de la Sociedad de Naciones. PITA, 2014 y HERRERA, 2014.

11 A fines de 1928, Paraguay tomó por la fuerza un punto fronterizo (Chaco boreal), a lo que Bolivia respondió ocupando otro de Paraguay. Ambos países rompieron relaciones diplomáticas. En la Conferencia Panamericana de ese año se autorizó la creación de una Comisión de Neutrales, liderada por Estados Unidos y representantes de Colombia, Cuba, México y Uruguay. Esta comisión sólo logró un intercambio de prisioneros, pero la tensión aumentó, por lo que se invitó a participar a Argentina, Brasil y Perú. Las hostilidades militares iniciaron en junio de 1932. Un mes más tarde, Saavedra Lamas sugirió al Comité que adoptaran una declaración donde se condenara el uso de la fuerza para la solución de los problemas territoriales, medida que fue aceptada y formó parte del Tratado Antibélico (firmado en Río en octubre de 1933). En agosto de 1932 ambos paises beligerantes escribieron a la Sociedad de las Naciones para protestar de las acciones del país vecino, pero no solicitaron que el organismo interviniera en la solución del conflicto. Argentina, Brasil, Chile y Perú ofrecieron mediar al Comité de Neutrales, pero la iniciativa no fue aceptada. RUDA, 1992, pp.33-34.

12 Se inauguró el 12 de junio de 1933 con la participación de representantes de 67 países. La mayoria de los participantes de la Conferencia buscó alcanzar un acuerdo para reestablecer el oro como patrón monetario internacional (el cual había sido abandonado por algunos países), pero el principal obstáculo para llegar a algún acuerdo lo constituyó el tema de las deudas internacionales (de países europeos con Estados Unidos). Este país se negó a discutir el tema de las deudas de guerra en la Conferencia, por lo que la reunión terminó en un fracaso aunque algunos países como México lograron obtener ciertos resultados en relación a la plata, a través de una serie de encuentros realizados entre productores y tenedores del metal y gracias a la alianza con Estados Unidos para firmar el Acuerdo de la Plata, uno de los pocos resultados concretos de la Conferencia. HERRERA, 2010, pp. 218-219; 223-227.

13 CA, carta de Manuel Puig a Alfonso Reyes, 19 de julio de 1933.
} 
en Chile debía mantener por correspondencia contacto diplomático, asi se lograria una alianza estratégica con los dos países. Reyes respondió rápidamente aceptando el encargo y anunciando los detalles de su viaje (el cual oficialmente quedaría como de vacaciones por cuestiones de salud), a lo que México responde dando el visto bueno y solicitando que antes de salir de Brasil enviara informes sobre la posición exacta que tenía ese país en torno al conflicto del Chaco. Agrega otro dato para su viaje a Chile: cuando el presidente Alessandri estuvo desterrado en París, Puig lo visitó de parte del presidente Calles. (Reyes, 2011, p.130-132).14

Al llegar a Santiago, en agosto de 1933, Reyes fue recibido como escritor y no como diplomático, por ello, de manera privada mantuvo una serie de reuniones con Cruchaga. En la primera de ellas el chileno se mostró complaciente con la propuesta mexicana, por lo que quedaron de reunirse en breve "con papeles en mano" para estudiar los acuerdos de las modificaciones al programa de la Conferencia. La buena predisposición del chileno le hizo pensar que podría obtenerse un acuerdo previo, y debido a que la reunión fue antes de lo previsto, Reyes necesitaba precisar instrucciones sobre la política mexicana para la próxima conferencia. En el mismo mensaje pedía disculpas por su impertinencia, pero queria expresar que consideraba al canciller argentino Saavedra Lamas una persona difícil, "capaz de echarlo todo a rodar por cuestión de celos personales, siendo necesario llevarle el genio y halagarlo". (REYES, 2011, p. 151).15

En una reunión posterior (31 de agosto de 1933), expuso formalmente los puntos de vista mexicanos sobre la futura Conferencia y el deseo de contar con su consejo y obtener un acuerdo. El chileno lo autorizó para manifestar a México su aprobación del capítulo económico continental que este país quería dar y expresó que aun y cuando su país había sido partidario del patrón oro, consideraba que la plata era la base de las transacciones monetarias, por lo que pensaba no habría problema en apoyar la adopción del bimetalismo. Sobre el tema "deudas y no intervención", le parecía oportuno y aplaudía la propuesta "sin reservas". Tras el encuentro, Cruchaga hablaría con el presidente para que nombrase a los delegados chilenos para la Conferencia, a quienes reuniría para explicarles el punto de vista mexicano, redactando también en dicha reunión los temas de interés de Chile, sobre los que le informaria. (REYES 2011, p. 157-159).

Al regresar a Río anotó en su diario: la delegación mexicana para la próxima Conferencia de Montevideo estará presidida por Puig, e integrada por Basilio Vadillo, Manuel J. Sierra, Eduardo Suárez, Pablo Campos Ortiz, y el que suscribe. Hizo también varias anotaciones sobre lo agitado que estuvo el ambiente diplomático en Río por la visita de mandatarios y diplomáticos, quienes se reunieron con la finalidad de formalizar el Pacto Antibélico impulsado por el ministro de Relaciones Exteriores de Argentina, Carlos Saavedra Lamas. ${ }^{16}$

Como representante de México Reyes firmó, pero suspicazmente anotó en su diario el descontento aclarando que no adhería. El comentario se relacionaba posiblemente con los recelos expresados con anterioridad sobre la personalidad y el protagonismo de Saavedra Lamas (REYES, 2011, p

\footnotetext{
14 La cancillería mexicana le comentó que el país tenía un "particularisimo interés" en que la reunión de Montevideo se orientara a rumbos económicos, amén de los problemas relacionados con el pacifismo. Por tanto, pronto presentarian una nueva redacción del capítulo económico de la agenda, pero para ello requiere que los países estén de acuerdo. Los temas a presentar serian: moratoria general, deudas internacionales de los países del continente; declaración conjunta de no intervención por deudas; y sistema monetario bimetalista. Le piden que siga preparando el camino porque como el observó en su último mensaje ni Uruguay ni Argentina estarán de acuerdo. (REYES, 2011, 143-146)

15 Reyes habia anotado dias antes en su diario un recordatorio: comentarle a Puig que se cuide mucho del "vidrioso" Saavedra Lamas. Puig tomó en cuenta esta observación y poco después le comentó que había escrito al argentino para preguntarle su opinión sobre el tema deudas, quien respondió de manera muy amable. REYES, 2011, pp. 146 y 153.

16 Conocido como Pacto Saavedra Lamas fue suscrito en Río de Janeiro el 10 de octubre de 1933, por México, Uruguay, Chile, Paraguay, Brasil y Argentina. Además de las declaraciones sobre el arbitraje como único medio legítimo para la conciliación, los artículos VI al XIV trata de la Comisión de Conciliación, la cual será la encargada de mediar en la controversia. Desde que se presentó la iniciativa en septiembre de 1932 hasta su firma en octubre de 1933 se realizaron una serie de discusiones. Saavedra Lamas contó con el apoyo de Brasil, pero no de Estados Unidos porque consideraban que disminuia la importancia del Pacto Briand-Kellog, pero posteriormente, en la reunión de Montevideo anunció su intención de ser parte del pacto (el cual finalmente ratificó después, al igual que otros países americanos y europeos que no estuvieron en un principio. RUDA, 1992, pp. 30-33.
} 
179). En el intento de arreglar este conflicto desde su desencadenamiento en junio de 1932 México buscó "universalizar" a través de la intervención de la Sociedad de Naciones mientras que argentina buscó hegemonizar sudamericanizando. ${ }^{17}$

\section{b) La puesta en escena. Montevideo}

El 26 de noviembre de 1933 Reyes arribó a Montevideo como parte de la delegación mexicana para participar de la VII Conferencia Panamericana, la cual se desarrolló del 3 al 26 de diciembre. Los objetivos eran claros: discutir las iniciativas de moratoria de deudas y el sistema monetario bimetalista (para confirmar los compromisos previos arreglados con Estados Unidos) y que se avanzara en la consolidación de un sistema jurídico interamericano. En ambos casos se buscaba comprometer a los Estados Unidos en su política del Buen Vecino (más allá del discurso), lo cual favorecería el próximo cambio presidencial en 1934 (CARRILLO, 2018, 245).

Antes de iniciar la delegación mexicana se reunió para organizarse durante los últimos días de noviembre y los primeros de diciembre de 1933. Ahí se definió que Reyes quedaría asignado para trabajar dos capitulos del programa: el I organización de la paz y el VI, intercambio intelectual. Dado que para este último pidió ayuda a Daniel Cosío Villegas como auxiliar técnico, se concentró a organizar el capítulo I en las siguientes reuniones realizadas en el hotel. La situación es desesperante, porque la propuesta está incompleta y teme que no se llegue a presentar nada "congruente". Además, anota, el jefe (Puig) quiere regresar cuanto antes a México, por lo que tiene una "descorazonada apatía". Por si fuera poco, la "bomba de la paz" que había ideado con Manuel J. Sierra ${ }^{18}$ fue anunciada en los periódicos esa tarde como una idea de la delegación mexicana para alcanzar una "tregua de Dios" en el Chaco mientras transcurría la Conferencia. La difusión de esta noticia empero, jugó a favor de la delegación mexicana. Desde Asunción, la "bomba de la paz" fue juzgada como una "noble idea", pero como ellos (los paraguayos) no quieren tregua, sino paz (pues la tregua sólo serviría para darles tiempo a los bolivianos de armarse). El hecho es que la idea ya había sido lanzada y el secretario Puig se había reunido con los delegados de Estados Unidos para discutirlas y al parecer se habian plegado. Esto no impidió que Reyes siguiera trabajando en el Código de la Paz, pese a que la actitud de Puig seguía desanimándolo (REYES, 2011, p. 188-190).

Al iniciar la Conferencia vino el primer golpe por lo que entre los días 5 y 9 de diciembre Reyes anotó su desazón: "nada era verdad", "sesiones secretas de escamoteos y públicas de faramalla. Me resisto a tomar nota de tanta vaciedad. Mucho trabajo y gasto inútil". Al dia siguiente el ánimo mejora, pues inicia el trabajo en las comisiones, aunque de una manera desordenada y con una retórica que exaspera a Reyes al punto de anotar "ganas de irse. Desmayo de todos. Soledad mía. Inutilidad de la Conferencia". A medida que avanzaba la Conferencia cambió nuevamente su estado de ánimo, mostrándose optimista al observar que finalmente se había discutido en público (no más en secreto) la propuesta mexicana, la cual si bien al inicio se vio amenazada ahora es retomada por los Estados Unidos, país que recomendó realizar una conferencia especial en mayo próximo (1935) en Santiago (REYES, 2011, pp. 190-191).

Esta (primera) versión del Código constaba de

\footnotetext{
17 Tras la firma del pacto, entre noviembre de 1933 y marzo de 1934, la comisión internacional (compuesta por representantes de España, Francia, Inglaterra, Italia y México) pudo realizar su trabajo (procurar el cese de las hostilidades). En mayo de ese año entregó su informe, en el cual expuso los principales obstáculos para una solución: creencia de los beligerantes de que podían mejorar su situación militar; intereses de varios paises por vender armas y equipo (excedente de la Primera Guerra). Así, indirectamente se mencionó entre los consejeros sobre los intereses que tenía Argentina a prestar apoyo al gobierno paraguayo, así como los estadounidenses apoyaban a los bolivianos. Esto generó que Estados Unidos y Brasil rechazaran el informe. HERRERA, 2014, pp. 184, 188, $192-193$.

18 Manuel José Sierra Méndez, hijo de Luz Mayora Carpio y de Justo Sierra Méndez. Estudió derecho, especializándose en derecho internacional público. Ingresó a la Secretaría de Relaciones Exteriores de México en 1905 con el puesto de escribiente en la Embajada de este pais ante Estados Unidos. Para 1928 se desempeñaba como jefe del Depto. Diplomático, cargo que mantuvo durante la década siguiente, cuando también formó parte junto a Genaro Fernández MacGregor, Eduardo Suárez, Óscar Rabasa y Fernando González Roa, de la Comisión de Codificación del Derecho Internacional. Según los informes estadounidenses, Sierra tenía mucha influencia dentro de la Secretaría (mas no fuera de ella), siendo "uno de los hombres más fuertes al interior de la Cancilleria", convirtiéndose en "el poder detrás del trono". Coautor de un primer borrador del Código de la Paz junto con Mac Gregor, pero que éste último no participó de la reunión en Montevideo, por lo que oficialmente quedaron como autores Reyes y Sierra. CARRILLO, 2018, p.143 y 235.
} 
102 artículos agrupados en cinco capítulos: Principios generales, Bases del sistema, Conciliación y creación de una Comisión Permanente, Arbitraje, Corte Americana de Justicia Internacional. La introducción se dedicó a justificar la necesidad de un nuevo medio jurídico ante la falta de coordinación de los medios previos, los cuales han demostrado ante los conflictos recientes no ser completamente eficientes (en relación al conflicto de Leticia y del Chaco, donde se había tenido que recurrir a organismos especiales o aceptar la intervención de la SDN). A manera de antecedentes jurídicos en el campo del derecho se hacen referencia a los tratados y convenciones anteriores, señalando sus alcances y sobre todo, limitaciones. El más reciente, el Pacto antibélico apenas firmado, presentaba un grave problema: la comisión de conciliación se forma recién al estallar el conflicto (igual que en el Pacto Gondra y la Convención de Washington). El Código recuperaba en un solo instrumento la lógica, organización y principios de éstos, así como los del proyecto de Maúrtua y Brown Scott sobre la Comisión Permanente de Conciliación y la Corte de Justicia. ${ }^{19}$

A su vez, los "Principios generales" plantean que cualquier tipo de guerra o conflictos entre naciones deben arreglarse vía la del derecho internacional para frenar las agresiones de todo tipo. Por ello se reconoce como agresor a cualquier Estado que -no importa qué fin persiga- declare la guerra a otro Estado; invada el territorio (o sus buques y aviones); bloquee la costa o algún puerto de otro país. Incluso, se prevé otro tipo de agresión menos visible, como la de ayudar a elementos que se formaron dentro de su país para atacar a otro. Si algún país se convierte en agresor los demás deben pronunciarse neutrales y utilizar los mecanismos de derecho internacional para restaurar la paz en respeto a los tratados acordados.

Para dar estructura a estas ideas y principios se sientan las bases del sistema a través de tres instancias clave: la Comisión Permanente de
Conciliación, Arbitraje y la Corte de Justicia Interamericana. Esta última es la primera instancia a la que se acudiría, y si decide que no puede intervenir puesto que el conflicto no tiene una solución jurídica, enviará el caso para ser sometido a la Comisión Permanente o al Arbitraje. En la situación extrema de que los interesados no quieran seguir ninguna de estas instancias, se aplicaran sanciones no coercitivas por parte de los otros Estados. Todas estas medidas estaban pensadas para evitar que los conflictos llegaran a una guerra, pero si los Estados ya habian iniciado hostilidades se les obligaría a suspenderlas durante el proceso de conciliación.

Para dar sustento a la creación de una Comisión Permanente de Conciliación se planteó con sumo detalle la manera en que ésta se integraría para asegurar la representatividad de los países miembros, así como la legitimidad de la elección de los cargos de presidente y vicepresidentes. Una vez conformado este grupo de expertos y personas de "alta moral, la Comisión se entendería directamente con los gobiernos para su actuación, aunque los países interesados en los casos de conciliación podian también nombrar otros agentes autorizados como cooperadores o intermediarios. Se buscaba otorgar a la Comisión un carácter permanente, con atribución para intervenir en un diferendo no sólo cuando alguno de los países involucrados lo solicitara, sino cuando la propia Comisión considerara que el conflicto perturbaría la armonía o la paz internacional. Su carácter ejecutivo implicaba que, en caso de urgencia, el presidente de la misma podría iniciar el procedimiento de conciliación, incluso antes de que se reuniera la Delegación Permanente. Tras estudiar el conflicto, la Comisión debe presentar un informe en un lapso de seis meses (a menos que las partes de común acuerdo decidan acortar o prorrogar este lapso). Dicho escrito no podía ser una sentencia, sino más bien una exposición que propondrá una solución "justa y equitativa" que

\footnotetext{
19 Nada se menciona sobre la Corte Permanente de Justicia Internacional que, si bien funcionaba desde 1921, fue recién en 1930 que intentó codificar el derecho internacional al reunir en una conferencia específica a numerosos juristas. El evento también fracaso, como señaló el jurista chileno Álvarez "la propia idea de codificación entrañaba -y estaba condenada a causar en lo sucesivo- muchos problemas que resolver". Para Álvarez, se estaba intentando construir algo que se encontraba aún "sobre cimientos inestables". DOMINGUEZ. 2019, p. 133, 137 y 141
} 
seria leída durante el proceso de conciliación. Para asegurar la permanencia de esto se preveía que los miembros de la Comisión percibirán honorarios (acordados por las partes en controversia, quienes lo sufragarán). Las decisiones deberán tomarse por mayoría de votos y no tendrá carácter de sentencia, sino de informe y recomendaciones, sobre el cual las partes deben pronunciarse en un plazo de seis meses. Si al cabo de éste no se pronuncian la Comisión redactará un acta especificando los términos del arreglo, el cual se haria público en ese momento.

En cuanto al Arbitraje, el Código proponia que se nombrara un árbitro o tribunal por acuerdo entre las partes, pero en caso de no haber acuerdo se nombrarían dos árbitros (si hubiese más de dos Estados en una controversia se designarian más miembros, pero siempre debe quedar en igualdad de números). Un tercer arbitro presidiria el Tribunal. Se sugeria que se recurriera a los miembros del Consejo Directivo de la Unión Panamericana, y de igual manera, si no se llegaba a un acuerdo sobre el lugar donde se reuniria el tribunal, éste sería fijado por la Unión Panamericana. Los agentes nombrados por los paises en conflicto debian entregar la documentación al Tribunal para que éste pudiera preparar la instrucción escrita con las pruebas. Posteriormente, se iniciarian los debates (los cuales serán privados y recuperados en actas firmadas), donde pueden presentarse nuevas pruebas con el consentimiento de las partes. El Tribunal debía deliberar de manera privada y secreta tomando decisiones por mayoria de votos para dar la sentencia arbitral, la cual tendría carácter obligatorio por lo que no se podia apelar. Al igual que en el caso de la Conciliación, los gastos serian cubiertos por los Estados litigantes.

A estos dos cuerpos se le sumaba el de la Corte Americana de Justicia Internacional, proyecto que recuperaba la iniciativa presentada por la diplomacia mexicana en la II Conferencia Panamericana, donde planteó la creación de una Corte Interamericana. Hacia finales de 1933 se retomó esta propuesta para dar una salida a la rivalidad entre Argentina y Estados Unidos por los medios utilizados para solucionar la guerra del Chaco al ofrecer una sintesis de las propuestas de ambos paises. (CARRILLO, 2018, 235-237).

El Código preveía que estaría compuesta por un representante de cada uno de los estados de la Unión Panamericana, quienes se dividirian para formar parte del Tribunal de Primera Instancia y el de Apelación, y para nombrar residente, vicepresidente y secretario. Todos permanecerian en sus cargos por cinco años para dar permanencia. Su jurisdicción, de carácter internacional, se remitía a la interpretación de un Tratado y Convención; la violación de una obligación; la reparación producida por dicha violación de una obligación; la interpretación de una sentencia dictada por el Tribunal y en general, todas las disputas que requieran un arreglo judicial. Además, podría ser un órgano consultivo que opinara sobre cualquier cuestión internacional (que no sea una disputa). El procedimiento que seguiria seria escrito y oral, dictando sentencia por mayoría de votos como las disposiciones indicadas para el Tribunal de Arbitraje (REYES, 2001, p. 579-604).

Pese a que la Conferencia de Montevideo señaló la importancia del proyecto presentado por la delegación mexicana sólo recomendó que por conducto de la Unión Panamericana se sometiera a la consideración de los Gobiernos miembros. ${ }^{20}$ Para Carrillo, aunque la propuesta era buena y detallada, los acontecimientos del momento jugaron en contra de su aprobación. La Guerra del Chaco entre Bolivia y Paraguay estaba en tregua gracias a los esfuerzos de la SDN, por ello aprobar el Código implicaba romper el delicado equilibrio alcanzado. Además, Argentina y Estados Unidos se aliaron durante la Conferencia, por lo que este último tuvo que apoyar el Pacto Antibélico que tanto preocupaba a Saavedra Lamas, posponiendo para la siguiente conferencia la discusión del Código. México no se resistió porque habia alcanzado varios de sus objetivos, confirmando su intención de ampliar su capacidad de negociación con Estados Unidos (CARRILLO, 2018, 258-230).

20 Ver transcripción de acuerdo en: https://www.dipublico.org/14729/codigo-de-la-paz-septima-conferencia-internacional-americana-montevideo-1933/ 


\section{Segundo intento (1935-1936)}

a) Tiempo de espera

El Código se mantuvo en espera. Mientras tanto, la vida diplomática de Reyes se dedicó, entre otras cosas, a participar en Río de Janeiro de una Conferencia como observador de las reuniones para dar fin a la guerra entre Perú y Colombia, paises que disputaron entre 1932 y 1934 una zona limitrofe en el Amazonas, conocido como el conflicto de Leticia. ${ }^{21}$ Finalmente, el conflicto llegó a su fin con la firma del Protocolo de Amistad y Cooperación entre ambos países el 24 de mayo de 1934. En palabras de Reyes, esto permitió que "los empeños pacifistas de la Sociedad de las Naciones, que tantos reveses han sufrido, se vieron asi coronados de éxito en forma que conforta la moral de América y del mundo".22

México había tenido una participación destacada en la solución del conflicto. El ministro mexicano Francisco Castillo Nájera fue el presidente de la Comisión Consultiva que nombró la Sociedad de Naciones. Los buenos oficios de los representantes mexicanos hicieron que ganara fama en la solución de conflictos, lo cual a su vez lo posicionó en el organismo internacional hasta tal punto que, pese a que había planteado poco tiempo antes que renunciaria a pertenecer a ésta, decidió permanecer en la Sociedad de Naciones (HERRERA, 2009, pp. 207-223).

Si bien esta mediación le hizo ganar una posición destacada en el ámbito internacional no tuvo el mismo impacto a nivel continental donde se mantuvo una tensión con Argentina por la forma en que protagonizó la resolución de la Guerra del Chaco. Por ello, Reyes escribió al coautor del Código, Manuel J. Sierra, como amigo y confidente del ámbito diplomático, para expresarle su malestar por las acciones del argentino Saavedra Lamas. ${ }^{23}$ El comentario hacía referencia a las últimas reuniones realizadas en Buenos Aires con el fin de negociar el fin de la guerra del Chaco. Efectivamente, se firmó un armisticio en junio 1935, así como las bases de un protocolo de Paz que sería discutido en la próxima conferencia panamericana de Buenos Aires. México no formó parte de estas últimas negociaciones pese a que trabajó durante los anteriores cinco años a través de la mediación realizada por la Sociedad de Naciones. ${ }^{24}$

Esto no impidió que México insistiera en dar legitimidad a su Código en otros escenarios internacionales. Por ello, Reyes escribió de nueva cuenta a Sierra para comentarle que se reuniria pronto en la ciudad de México el VII Congreso Científico Panamericano (México, 9-17 de septiembre de 1935). Dado que existian circunstancias favorables por la participación de diplomáticos mexicanos, el Lic. Garrido, quien actuaba como secretario de la Sesión de Ciencia Jurídica, presentó una síntesis del Código de La Paz, el cual escribió "sobre la rodilla y a 200 por hora", con el fin de que fuera incluido en dicho Congreso. ${ }^{25}$ La iniciativa fue aprobada en dicho congreso, aunque de manera difusa. La resolución explicitaba que los gobiernos de América adoptasen un Código de Paz para que en lugar de recurrir a la fuerza se solucionaran los conflictos mediante el arbitraje mientras los otros

\footnotetext{
${ }_{21}$ El conflicto había iniciado en septiembre de 1932 cuando un grupo armado de peruanos tomó la ciudad de Leticia. Ante esto, el gobierno peruano decidió apoyarlos e iniciaron las acciones militares por ambos países. Al ser asesinado el presidente peruano Luis Miguel Sánchez Cerro, subió al poder el Gral. Óscar Benavides, quien era amigo del presidente colombiano. Poco después, Perú acepta entregar la zona de conflicto (Leticia) a una comisión de la Sociedad de Naciones, la cual tardó un año en analizar las posibilidades para solucionar el conflicto. A cambio, Colombia entregó a Perú una isla, una guarnición y los prisioneros de guerra. La guerra llegó a su fin mediante la firma del Protocolo de Río de Janeiro (1934)

22 REYES, 2001, tomo II, pp. 154.155.

23 Reyes comenta a Sierra que Saavedra Lamas intentó aplazar el encuentro entre los cancilleres de Bolivia y Paraguay (una vez que ambos estaban ya reunidos en la Casa Rosada). Por suerte, comenta, Macedo Soares amenazó con retirarse si no se realizaba la entrevista, por lo que pese a los intentos de Saavedra Lama se dio la reunión. CA, carta de Alfonso Reyes a Manuel J. Sierra, Río de janeiro, 5 de julio de 1935. En respuesta, Sierra se queja del "nefasto Saavedra" señalando el hartazgo y resentimiento de México de que Argentina y Brasil, en especial el primero, le "atajara" el paso tanto en la VII Conferencia Panamericana, como en el caso de la guerra del Chaco y en el nombramiento de Suárez en Ginebra. CA, carta de Manuel J. Sierra a Alfonso Reyes, México, 2 de agosto de 1935.

24 Pese a la insistencia de México de que la solución del conflicto fuera resuelta por la instancia internacional, ante el retiro de Inglaterra y Francia (preocupadas por el nazismo), se conformó un grupo de mediadores con representantes de los países limitrofes, Estados Unidos y Uruguay, quienes lograron que los paises aceptaran firmar el armisticio, más por el cansancio de la guerra que por una nueva propuesta. HERRERA, 2014, pp. 206-207.

25 CA, carta de Manuel J. Sierra a Alfonso Reyes, México, México, 22 de agosto de 1935 y de Manuel J. Sierra a Alfonso Reyes, México, 9 de septiembre de 1935
} 
estados mantenían una posición neutra. ${ }^{26}$

En julio de 1936 Reyes regresó a Buenos Aires como embajador por segunda ocasión. El cambio se debia, en parte, al interés del gobierno mexicano de contar con su experiencia para una serie de importantes eventos que se realizarian en esta ciudad en el año de 1936. La más relevante para el panamericanismo era la III Conferencia Extraordinaria Interamericana de Consolidación de la Paz a celebrarse en Buenos Aires entre el 3 y el 22 de diciembre de 1936. En septiembre de ese año se celebraban también otras dos conferencias en las que participaría Reyes, el XVI Congreso de la Federación Internacional de P.E.N. Clubs y la de Cooperación Intelectual. En la primera se reunieron casi por partes iguales un nutrido grupo de intelectuales europeos y americanos, quienes al debatir sobre literatura se adentraron en la política, al pronunciarse algunos a favor y otros contra el avance del totalitarismo. ${ }^{27}$ En la segunda reunión los intelectuales se dedicaron a analizar las relaciones culturales entre Europa y América Latina. Aunque en las conversaciones se utilizó un tono político más neutro el debate se tensionó ante el planteamiento de Reyes de que América había alcanzado la mayoría de edad por lo que podía y debía ser considerada un baluarte de la cultura occidental. ${ }^{28}$

Al mismo tiempo, Reyes envió cuatro informes a la Secretaría de Relaciones Exteriores para ir precisando los criterios que se presentarian en la reunión panamericana de diciembre de ese año. El tercero era una memoria titulada "Coordinación y perfeccionamiento de los instrumentos internacionales existentes para la consolidación de la paz", elaborada a solicitud de la Secretaría en septiembre de 1936, y que pretendia continuar con el trabajo trazado en el Código de Paz. Para entrar en materia, Reyes escribe un extenso análisis del tema, en el cual presentaba la situación política mundial de posguerra y de la situación particular de América en el nuevo escenario político. Delineó los intentos de organización mundial hasta ese momento concebidos: del Estado mundial original a la idea de la SDN (con su contradicción entre el ideal de unidad y el método de desunión) pasando por los múltiples imperialismos (romano, chino) y la idea moderna del mercado mundial con el desarrollo de la burguesía. En el tema general, justificó la necesidad de que el continente americano tomara "precauciones de paz" ante las amenazas mundiales. En los antecedentes del asunto comenzó a precisar por qué pese a que en las Conferencias Panamericanas se trataron temas de arreglo pacífico de las cuestiones internacionales, esto sigue siendo limitado. Con esta explicación el terreno estaria preparado para que en la siguiente Conferencia se redibujara el Código de la Paz (el cual enfatiza, se debe a Manuel J. Sierra la principal labor, siendo la suya más modesta). Por ello sugiere que como complemento debe leerse el opúsculo realizado por Sierra, titulado "México y la Conferencia de Montevideo, 1934".

Era probable que existieran dificultades en aceptar la propuesta mexicana, por lo que Reyes consideraba necesario remitir previo a la Conferencia, un ejemplar a cada gobierno y a sus delegados, utilizando la gestión de los representantes mexicanos en conversaciones y entrevistas para asegurarles que se trataba de un bosquejo que podría ser mejorada según sus comentarios. Consideraba necesario que el Código se percibiera como un organismo regional de la Sociedad de las Naciones para sortear, por ejemplo, la oposición que mostró Brasil en la Conferencia de Montevideo de que como miembros de la Corte de La Haya,

\footnotetext{
26 Secretaría de Relaciones Exteriores, Acta final del Séptimo Congreso Científico Americano, consultado en https://www.dipublico. org/101016/septimo-congreso-cientifico-americano-cuarto-congreso-cientifico-panamericano-mexicod-f-9-17-de-septiembre-1935/ 27 Pese a que el gobierno argentino intentó mantener los debates lejos de las polémicas políticas fue imposible que los participantes las evitaran. El principal enfrentamiento se dio entre Tomaso Marinetti, representante de los escritores italianos que defendian la Italia fascista y Emil Ludwil, representante de los escritores alemanes anti nazis. Reyes informó al gobierno mexicano sobre estas tensiones desestimando que fuera a pasar a mayores, aunque informando sobre el impacto que tuvieron en la prensa y en la opinión pública estudiantil de derecha. Pita, 2014, pp. 143-145

${ }_{28}$ Reyes fue nombrado conferencista magistral para abrir el debate. Su extensa participación justifica el porqué América no es una especie de árbol trasplantado de Europa, sino un nuevo mundo, que pese a tener su "propio compás y ritmo" ha vivido intentando alcanzar las etapas europeas, viviendo en un proceso de acelerado tiempo histórico. Por todo esto finaliza su argumentación de manera provocativa al solicitar al tribunal de pensadores que, asi como lo había hecho hace tiempo España, reconozcan que la inteligencia americana ha conquistado el derecho a la ciudadanía universal. PITA, 2014, p.146-150.
} 
no podía defender la creación de un Tribunal de Justicia Interamericano. ${ }^{29}$ No debía plantearse como una emancipación de la tutela de Ginebra, sino como un paso para dar mayor jerarquía a los asuntos estrictamente americanos. El arte de la diplomacia estaba en la sutileza. Recordaba que cuando el Código se presentó en Montevideo se hizo como una contribución académica y no como un tema de discusión de las comisiones porque en ese momento el argentino Saavedra Lamas pretendía difundir en la reunión su Pacto Antibélico y habría sido "poco elegante el proponer una competencia inoportuna". Además, en esos días había una esperanza para resolver la Guerra del Chaco, por lo que no era conveniente contemplar el Código dado que éste señalaba el concepto de agresor (que recaía sobre Bolivia). Como las circunstancias habian cambiado ahora era propicio que México presentara el Código como propuesta oficial, aunque abierta a debates y correcciones. ${ }^{30}$

\section{b) ¿Neutralidad y paz americana?, Buenos Aires, 1936}

Los preparativos se intensificaron hacia finales de noviembre de 1936 cuando llegó la delegación mexicana a Buenos Aires. ${ }^{31}$ El que ésta estuviera presidida por Castillo Nájera, quien tenía vasta experiencia en la Sociedad de Naciones daba cuenta del interés que tenía el país de poner a sus mejores negociadores en juego. El mismo día del arribo, tras cooptar las instalaciones de la legación, Castillo Nájera y Reyes realizaron una visita protocolar a Saavedra Lamas, quien un día antes habia recibido la notificación de haber ganado el Premio Nobel de la Paz. ${ }^{32}$

Como advirtió Reyes a la Secretaría de Relaciones Exteriores, la conferencia había sido convocada por el presidente de Estados Unidos, Franklin D. Roosevelt, quien se proponía asegurarse la neutralidad de los países americanos ante una posible guerra europea. La Secretaria estuvo muy atenta a la preparación del evento. Envió a Reyes un oficio en el mes de julio con las observaciones que formuló el gobierno mexicano, señalando cuáles fueron aceptadas por el Consejo Directivo de la Unión Panamericana. Como podría ver por el programa definitivo que enviaban, se habian enfocado en presionar para que se aceptara el Código de la Paz en el temario, el cual no había sido incorporado como tal "por más que la idea que sugerimos de que todos los instrumentos internacionales existentes para la consolidación de la Paz sean substituidos por un instrumento único". En su lugar quedó en el programa como un apartado (b) del primer eje sobre la organización de la Paz en su primer punto dedicado a los "Métodos de prevención y solución pacifica de los conflictos interamericanos" bajo el título "Coordinación y perfeccionamiento de los instrumentos internacionales existentes para la consolidación de la paz, y conveniencia de incorporarlos en un instrumento único". Por esto, sería posible que Reyes realizara el trabajo encomendado presentando una nueva versión del Código de la Paz, diferente de la presentada en la Conferencia de Montevideo. ${ }^{33}$

Reyes fungía también como secretario de la Comisión Mexicana de Cooperación Intelectual, por tanto, presentaría en dicho evento un trabajo

\footnotetext{
29 Aunque el proyecto inició antes de la Primera Guerra Mundial, fue desde 1919 en la Conferencia de Paz que esta se organizó al crear un comité internacional encargado de presentar un proyecto para una futura corte, el cual estuvo compuesto por juristas reconocidos como Elihu Root. Aunque los paises latinoamericanos se mostraron interesados la ratificación del estatuto se dio años después, en otros casos nunca (Argentina, Costa Rica, Guatemala y Nicaragua). México, Ecuador y Honduras ni siquiera firmaron el estatuto. El interés cambio en 1929 cuando tras el aumento de jueces (de once a quince), las delegaciones latinoamericanas vieron la oportunidad de obtener tres asientos. WEHRLI p. 232-234.

30 REYES, 2001, (tomo 1), pp. 541-592.

31 Amén de Campos Ortiz, participaron en la delegación Francisco Castillo Nájera (presidente de la representación y embajador de México en Estados Unidos). Alfonso Reyes (delegado plenipotenciario y embajador de México en Argentina), Ramón Beteta (subsecretario de Relaciones Exteriores), Juan Manuel Álvarez del Castillo (ministro de México en República Dominicana), Agustín Leñero (asesor técnico y cónsul gral. de México en París), Luis Garrido y Antonio Espinosa de los Monterios (profesores de economía de la UNAM, quienes fungieron como secretarios de la delegación), Rafael Fuentes Jr. y Fernando Lagarde (secretarios), Salvador Duhart (prensa), el diputado Alejandro Gómez Magaña (observador). Diario de Alfonso Reyes, p. 68.

${ }_{32}$ Los recelos sobre el Ministro Argentino se mantenían. Mientras trabajaban en las sesiones de la delegación antes de iniciar la conferencia recibieron la visita del secretario de estado de Estados Unidos, Summer Wells, quien les habla de "las intrigas" de Saavedra Lamas. REYES, 2011, pp. 65-67.

33 Los ejes del programa fueron: 1. Organización de la Paz; 2. Neutralidad; 3.Limitación de armamentos; 4. Problemas Jurídicos; 5. Problemas económicos; 6. Cooperación intelectual. CA, oficio de Ramón Beteta a Alfonso Reyes, México, 3 de agosto de 1936.
} 
sobre la enseñanza de la paz y la educación para la paz. Estas propuestas compartían un objetivo: apoyar la iniciativa de la Sociedad de Naciones (a través de Cooperación Intelectual, por alcanzar el desarme moral y material). ${ }^{34}$ Estos se diferenciaban porque mientras la primera era concebida como una preparación desde el punto de vista intelectual, la segunda era una preparación moral para "formar el carácter en los individuos y grupos sociales". En concreto, se pensaba en un intensivo plan de formación en las escuelas a través de actividades escolares, extraescolares, así como el uso de la radio y el cine con fines educativos. Además de las actividades escolares sugeridas, la propuesta planteaba otras extra escolares y el uso de la radio para difundir este programa (PITA, 2014, pp. 40-44).

A esta propuesta mexicana se sumó la revisión del Código de Paz, la cual consumió su tiempo y energía pocos días antes de iniciar la Conferencia. Exhausto por el trabajo escribió a Manuel J. Sierra para expresarle cuánto había echado de menos su colaboración para rehacerlo, y el temor que tenía de haber desvirtuado su obra. Le aclaró que las modificaciones realizadas procedian de los estudios del internacionalista Francisco J. Álvarez Fáller, con quien imagina concordar en varios puntos de vista. Espera que la obra sea de su agrado y finaliza asegurándole "El Código sigue su camino. ${ }^{35}$ Aunque en su diario se asume como único autor de la reestructura, la segunda versión del Código fue realizada con la ayuda de Pablo Campos Ortiz. ${ }^{36}$

Efectivamente, el texto sufrió algunas modificaciones para "atemperar su belicosidad" y se añadieron los artículos 103 y 104, bajo el subtítulo de transitorios para aclarar que dos aspectos del artículo 12 dedicado a la creación de una Comisión Internacional Americana de Conciliación: el que menciona que los miembros pueden ser elegidos por primera vez por el consejo director de la Unión Panamericana (por mayoría de votos) y el que aclara que si algunos de los países contratantes decide denunciar este tratado o retirarse, los miembros de la comisión permanente de conciliación o de la corte americana de justicia que representan a ese estado seguirian en sus funciones por el tiempo que fueron nombrados. ${ }^{37}$

La propuesta no fue presentada finalmente porque México decidió actuar de manera pragmática para facilitar otros acuerdos, y sobre todo, acercarse a Estados Unidos y Argentina. También sacrificó una propuesta contenida en el Código, la de crear una Corte de Justicia Interamericana para evitar tensiones con los países que se oponian (Brasil, Argentina y Estados Unidos). ${ }^{38}$ Como mencionó Reyes, se optó por posponer nuevamente su debate a la Conferencia de Lima en 1938. Mientras esto sucediera, Perú propuso que se creara una comisión de expertos que analizarian el proyecto y darian sus conclusiones en Lima. ${ }^{39}$ (CARRILLO, 2018, 307). Por último, Reyes

34 Como explicaba el presidente de la Comisión Mexicana de Cooperación Intelectual, Luis Sánchez Pontón, en la SDN se presentaban dos tendencias pacifistas, una se preocupa por lo material, el desarme militar; la otra, el desarme moral, que a largo plazo prepara los "espiritus". A la primera la llaman práctica y realista y a la segunda idealista, y, por ende, irrealizable, pero no es asi. Para poder alcanzar el primero en lo concreto debe establecerse mecanismos de paz permanente a través de tratados internacionales (del cual el Pacto de las Naciones con el que se originó la SDN sería el primero). El principal obstáculo para el desarme moral es el patriotismo, entendiendo por esto el sentimiento de odio, de supremacía y de dominación sobre los demás pueblos". La paz requiere de una obra de "educación y convicción". COMISIÓN MEXICANA DE COOPERACIÓN INTELECTUAL, 1937, pp. 6-7; 9-10.

35 CA, carta de Alfonso Reyes a Manuel J. Sierra, Buenos Aires, 7 de diciembre de 1936.

36 Pablo Campos Ortíz (1898-1963) fue un abogado y diplomático mexicano, oriundo de San Juan del Rio, Querétaro estudió en México y en Río de Janeiro. Tras ingresar al servicio diplomático en 1923 ocupó diversos puestos. En la Conferencia de San Francisco realizada en abril de 1945 le correspondió firmar como representante de México la Carta Constitutiva de la recién creada Organización de las Naciones Unidas (ONU). Falleció el 14 de junio de 1963 cuando se desempeñaba como Subsecretario de Relaciones Exteriores.

37 Reyes, 2001, pp. 578, 603-604. Cabe mencionar que el comentario sobre estos cambios fue realizado por el autor de la compilación documental, Victor Díaz Arciniegas en una breve presentación de la transcripción del Código.

${ }_{38}$ Auqnue no se aprobó el proyecto, varios paises se mostraron favorables a la creación de una Corte en especial los del Caribe, América Central y alguno de los países andinos. Sin embargo, el Cono Sur no era favorbale por distintos motivos. Brasil expuso que ya se habian adherido a la corte de La Haya por lo que consideraba perjudicial.En realidad lo que le preocupaba que de crearse esta instancia interamericana se creara un bloque con los paises hispanoamericanos capaz de oponerse a ellos y a Estados Unidos. Chile se oponía porque le parecia riesgoso tener una doble jurisprudencia entre cortes, además de que sería costoso y dificil encontrar jueces con el perfil requerido para representar a los páises latinoamericanos en ambas instancias. Argentina temía que una instancia interamericanareforzaria el particularismo continental, y con ello reforzaria el panamericanismo. WEHRLI, 2016, p. 240-242,

39 Oficialmente, las resoluciones de la Conferencia de Buenos Aires plasmaron en el artículo XXVIII que debido a que sus capítulos habian sido estudiados por separado en distintas Comisiones dedicadas a la Conciliación, el Arbitraje y el Arreglo Judicial Internacional, el Código no había sido considerado en su totalidad como un conjunto orgánico. Por ello, era imposible agotar su estudio en esa Conferencia, remitiendo su estudio a un comité de expertos de la Codificación del derecho Internacional, quienes deberian incluirlo entre los trabajos que presentarian en la siguiente Conferencia; es decir, un proyecto de coordinación de los instrumentos de paz americanos. UNIÓN PANAMERICANA, 1936, P 61 
apuntó con gusto cómo el discurso que pronunció Beteta en nombre de México fue ovacionado por el público, hecho que produjo la rabia de Saavedra, quien "clavó las uñas debajo de la mesa y sin querer se encontró con el timbre, que empezó a sonar a deshora" (Reyes, 2012, pp. 71-72).

Un par de meses después de la Conferencia Panamericana, la delegación mexicana que participó en Buenos Aires envió otro memorándum a la Secretaría de Relaciones Exteriores para indicar qué medidas debía realizar el gobierno para cumplir con lo estipulado, tanto en las convenciones escritas como en las resoluciones aprobadas. Hacía hincapié en aquellas medidas urgentes relacionadas al Código de Paz: la reunión de un Comité de Expertos para discutir sobre la codificación del derecho internacional, en el mes de abril de 1937 en Washington. Lo que quedara de esta propuesta sería definitivo para el Comité de Expertos, y, por consiguiente, inadmisible de volverse a presentar en la siguiente Conferencia. Si bien en México aún no se había constituido la Comisión Nacional de Codificación, se tenía una posición "clara e inequivoca" sobre el tema, por lo que propusieron hacer una publicación especial en la que se incluyera lo expresado por el gobierno en esta materia en mensajes del Ejecutivo, notas diplomáticas, declaraciones del presidente o del secretario de Relaciones Exteriores. Sugirieron también al gobierno que se presentara un trabajo preparado por la Secretaria de Relaciones Exteriores ante el Comité de Expertos, en el cual se vislumbrara, con claridad (utilizando cuadros comparativos), que las disposiciones contempladas en su propuesta habian sido aprobadas y que sólo se trataba de declarar que el ordenamiento realizado era una "compilación auténtica", que merecía como tal la aprobación de los otros gobiernos americanos. ${ }^{40}$

Reyes regresó a México en 1938 y se hizo cargo de la Casa de España, pero no olvidó el Código, recurriendo a su primer coautor, Manuel J. Sierra, para mantener viva la propuesta. Próximo a realizarse la Conferencia Panamericana de Lima (1938), le escribió nuevamente para preguntarle si había pensado sobre el tema. Recuerda haberle enviado en 1936 la segunda versión que realizó (con ligeros retoques y revisión de estilo). En el ejemplar enviado se puso en letra pequeña las novedades, y en grande, lo que se piensa puede hacerse en el futuro. Le confesó que esto fue una sugerencia de Campos Ortíz, que habia aceptado a regañadientas. Aun así cree que se puede limpiar el trabajo -de aquello "que solo aceptamos por cortesia y estrategia"-, para dejar un buen trabajo, básico, lo que facilitaría su aprobación en el Congreso. Le pide piense en su propuesta dado que la fecha se acercaba. ${ }^{41}$

Sin embargo, el Código tampoco fue tratado en la Conferencia de Lima, la cual pospuso nuevamente el debate porque, si bien habían alcanzado el acuerdo con diez países latinoamericanos, los de mayor peso (Estados Unidos, Argentina y Brasil), se oponian a la creación de una Corte Interamericana. Además, México debía lidiar con las tensiones existentes con Estados Unidos a raíz de la reciente expropiación petrolera, por lo que la delegación mexicana optó por no insistir en el tema y posponerlo una vez más. Así, el Código se convirtió en "un comodín que servía a México como mecanismo de presión, pero del que podía desprenderse sin complicaciones" (CARRILLO, 1998, 358).

Reyes no sacó el dedo del renglón. En 1954. posiblemente llevado por el deseo de dejar en orden su propia historia como diplomático, escribió a Sierra para recordarle que él era el "hombre del Código de la Paz". 42 Poco después, contactó a Campos Ortiz para expresar que seguía considerando el Código como un "antecedente precioso". Por ello y dado que Campos seguía relacionado

40 Archivo Histórico-Diplomático, Secretaría de Relaciones Exteriores (AHSRE), Memorándum de la delegación de México a la Conferencia Interamericana de Consolidación de la Paz, 8.3.1937, exp. LE-340, ff. 16-19.

41 CA, carta de Alfonso Reyes a Manuel J. Sierra, Río de Janeiro, 11 de julio de 1938. En una carta anterior, Reyes incitó a Sierra para que publicara una pequeña historia sobre algunos de los problemas de derecho internacional en el continente, tema sobre el que no sólo es un experto, sino que tiene información de primera mano. CA, carta de Alfonso Reyes a Manuel J. Sierra, Buenos Aires, 24 de septiembre de 1937. Efectivamente, Sierra publicó el artículo la enseñanza moderna del derecho internacional público en Revista de la Escuela Nacional de Jurisprudencia, tomo I, núm. 1, enero-febrero, 1939, a éste le siguió años después "Tratado de derecho internacional público" (1947) y otros libros en las décadas siguientes.

42 CA, carta de Alfonso Reyes a Manuel J. Sierra, México, 16 de junio de 1954 
a la Secretaría (ocupando el cargo de Oficial Mayor), le preguntaba si se lo habia retomado en la Conferencia Panamericana de Bogotá de 1948 (origen de la Organización de Estados Americanos, OEA), porque ahí se redactó un documento sobre los recursos pacificos (en el cual esperaba se citara como antecedente "nuestro viejo sueño".43 Campos respondió agradeciendo que recordara su participación en el proyecto y prometiéndole enviarle un memorándum con los datos relacionados. ${ }^{44} \mathrm{~A}$ los pocos dias Reyes escribe de nueva cuenta para decirle que no había recibido aún el memorándum y quería conservarlo en su archivo personal. No podía "ser indiferente a la historia de este asunto", de la cual citando a Quevedo para representar su actuación dijo: "Yo, el menor padre de todos los que hicieron este hijo"45 Tras recibir el memorándum escribió para agradecerle el envío, expresando "es más de lo que yo quería".46

\section{Conclusión}

Según explicaba Antonio Gómez Robledo, el Código no se aprobó porque era "un pacto muy coherente de soluciones pacificas, con definiciones muy precisas y muy severas de la agresión, con arbitraje obligatorio para toda clase de disputas, y contempla, por remate de todo, la creación de una corte americana de justicia internacional".47 Creemos que el fracaso de la propuesta no radicó en la severidad de su contenido puesto que en realidad en ninguna de las tres conferencias panamericanas se presentó y discutió la propuesta. Ante la falta de apoyo de algunos paises, México decidió retirarla una y otra vez. ¿Esperaba un contexto más favorable para su discusión o su interés no radicaba en sí mismo, sino en su poder como instrumento de negociación? Para Carrillo, la respuesta radica en el pragmatismo de la diplomacia mexicana, la cual sacrificó el Código en pos de jugar "un papel crucial como articulador de las coaliciones". (CARRILLO, 1998, 401).

Es necesario pensar esta afirmación. Es evidente que, a nivel continental, las coaliciones fueron fluctuando a un ritmo acelerado en el período. Esto se relaciona con la intensificación del panamericanismo, el cual tuvo en la década de 1930 una época dorada, no porque se hayan alcanzado todos los acuerdos, sino porque se intensificaron los debates al modificarse el status quo, no solo entre los países latinoamericanos, sino también, entre estos y los Estados Unidos. La Conferencia de Montevideo abrió el período con la impresión de que, ante la política de buena vecindad, Estados Unidos no podía imponerse (al menos no como lo venía haciendo anteriormente). Esto dio margen para que los principales países de América Latina disputaran un papel hegemónico, sobre todo, en relación a los grandes conflictos (el de Leticia y el Chaco). Aunque se trataron numerosos temas en la agenda panamericana del periodo, las alianzas se tejían tomando en torno a la posición que tomaron en estos conflictos. Estados Unidos y Argentina disputaron su liderazgo en el continente, pero finalmente llegaron a un acuerdo con el fin de restar jurisdicción a la Sociedad de Naciones de los conflictos en el continente. México perdió la apuesta de que este organismo internacional tuviera mayor injerencia, pero terminó secundando las propuestas americanas (BARRERA, 2001, pp. 18-19).

El Código sirvió para representar a México como un país que defendía los mecanismos de arbitraje y conciliación. Con ello, construía una nueva representación internacional que buscaba borrar su imagen sangrienta de la revolución y los primeros años de la pos revolución. En su lugar, la paz se convertía en un eje discursivo que vertebraba la imagen que se queria dar de la nueva política exterior mexicana, que recuperaba

43 CA, carta de Alfonso Reyes a Pablo Campos Ortiz, México, 20 de agosto de 1954.

44 CA, carta de Pablo Campos Ortiz a Alfonso Reyes, México, 3 de septiembre de 1954. Efectivamente, en la reunión de 1948 se suscribió el Pacto de Bogotá titulado Tratado Americano de Soluciones Pacíficas. Uno de sus autores, Ernesto Enríquez, expresó en una conferencia que sostuvo en México ese mismo año, que para ellos habia sido de gran importancia la presentación que habia hecho México del Código de la Paz en Montevideo, al cual describió como un "admirable documento que trato de coordinar y completar todos los instrumentos de paz interamericanos". VALDÉZ, 1997, 31-32.

45 CA, carta de Alfonso Reyes a Pablo Campos Ortiz, México, 8 de septiembre de 1954

46 CA, carta de Alfonso Reyes a Pablo Campos Ortiz, México, 9 de septiembre de 1954

47 Citado en DÍAZ, 2001, p. 79 
el espiritu de la Doctrina Carranza y Estada, sin necesidad de caer en una postura intransigente. Como señala Guillermo Palacios al estudiar la intensa relación entre este país y los de Sudamérica, los conflictos interamericanos de esta década (más que la cooperación en tiempos de paz), permitieron que México se involucrara de lleno en la política internacional. Con ello, abandonó el leit motiv del período anterior signado por la búsqueda del reconocimiento, rompiendo con el aislamiento (Palacios, 2011, pp. 267-268). Es probable también, que el intento de México por impulsar el Código haya estado relacionado con la intención de "poner un obstáculo adicional a las reclamaciones hegemónicas de los Estados Unidos" (WEHRLI, 2016, p. 237).

Esto nos lleva nuevamente a pensar en la compleja relación entre los países latinoamericanos y la Sociedad de Naciones durante el período que estudiamos. Así, mientras algunos se alejaron, otros como México, se incluyeron a un ritmo acelerado, aumentando su presencia. Si esta relación es compleja, al triangularlo con la del panamericanismo, se observa un proceso de internacionalización cargado de tensiones, pero también de nuevos escenarios que no se habian observado con tanta claridad en la década anterior. Así, paises latinoamericanos se involucraron en problemas europeos y viceversa, el organismo internacional intervino como árbitro en conflictos americanos. Esta situación fue aprovechada por México, el cual encontró un lugar en el concierto de las naciones al defender simultáneamente una postura universal y panamericana, (o mejor dicho americana en el sentido más amplio). En este sentido, el Código de la Paz es entendible no solo como mencionó Carrillo como una moneda de cambio dentro del ámbito panamericano, sino también, en el marco internacional. Al incorporar las herramientas juridicas anteriores (principalmente americanas), pero crear instancias regionales (La Corte Permanente y el Arbitraje,) no negaban la jurisdicción de La Haya ni de la Sociedad de Naciones, pero otorgaban a los países americanos mayor control sobre los procesos.

\section{Bibliografía}

COMISIÓN MEXICANA DE COOPERACIÓN INTELECTUAL. Organización y trabajo. México: DAPP, 1937.

BARRERA AGUILERA, Óscar Javier. La Guerra del Chaco como desafio al panamericanismo: el sinuoso camino a la Conferencia de Paz de Buenos Aires, 1934-1936. Anuario Colombiano de Historia Social y de la Cultura, [Bogotá], v. 38, n. 1, p. 179-217, enero. 2011.

CARRILLO REVELES, Veremundo. México en la Unión de las Repúblicas Americanas, El panamericanismo y la politica exterior mexicana, 1889-1942. 2018. Tesis (grado de Doctor en Historia) - El Colegio de México, Mayo, México 2018.

DOMINGUEZ BENITO, Héctor. "Cimientos inestables: los juristas latinoamericanos y el debate sobre la codificación del derecho internacional en 1930" In: LEÓN, Fabián Herrera; Yannick, Wehrli (ed.), América Latina y el internacionalismo ginebrino de entreguerras: implicaciones y resonancias. México: Dirección General del Acervo Histórico Diplomático, 2019. p. 129-157.

HERRERA LEÓN, Fabián. La politica exterior mexicana en la Sociedad de Naciones ante la Guerra del Chaco y el conflicto de Leticia, 1932-1935. México: Secretaria de Relaciones Exteriores, 2009.

HERRERA LEÓN, Fabián. México en la conferencia económica mundial de Londres: el Acuerdo de la Plata de 1933. América Latina en la Historia Económica, n. 34. jul./dic. 2010. p. 209-234. DOI: https://doi.org/10.18232/ alhe.v17i2.445

HERRERA LEÓN, Fabián. México y la Sociedad de Naciones, 1931-1940. México: Secretaría de Relaciones Exteriores, 2014.

PALACIOS, Guillermo. Historia de las relaciones internacionales de México, 1821-2010. América del Sur. México: Secretaría de Relaciones Exteriores, 2011.

PITA GONZÁLEZ, Alexandra. Educar para la Paz. México y la Cooperación Intelectual Internacional. México: Secretaría de Relaciones Exteriores, 2014.

REYES, Alfonso. Misión diplomática. Tomo I y II compilación y prólogo de Víctor Díaz Arciniega. México: Fondo de Cultura Económica, Secretaria de Relaciones Exteriores, 2001.

REYES, Alfonso. Diario. Vol. III 1930-1936. Edición, introducción y notas, apostillas biográficas, cronologia e indice de Jorge Rueda de la Serna. México. Fondo de Cultura Económica, 2011.

RUDA, José Maria. Carlos Saavedra Lamas. El apogeo de la política exterior argentina. Consejo Argentino para las Relaciones Internacionales, n 3, noviembre 1992. 1-38. Disponible en: http://www.cari.org.ar/pdf/ diplomaticos03.pdf. Accedido en: 20 ago 2019

SCARFI, Juan Pablo, The Hidden History of International Law in the Americas: Empire and Legal Networks, Oxford, Oxford University Press, 2017.

SCARFI, Juan Pablo. El imperio de la ley. James Brown Scott y la construcción de un orden juridico interamericano. Buenos Aires: Fondo de Cultura Económica, 2014. 
TAMBURINI, Francesco. Historia y destino de la "Doctrina Calvo": ¿Actualidad u obsolescencia del pensamiento de Carlos Calvo? Revista de Estudios Histórico-Jurídicos, Valparaiso, n. 24, p. 81-101, 2002. DOI: https://doi. org/10.4067/S0716-54552002002400005

UNIÓN PANAMERICANA, Conferencia Interamericana de Consolidación de la Paz. Buenos Aires: Imprenta del Congreso de la Nación Argentina, 1936.

VALDÉS TREVIÑO, Francisco. Alfonso Reyes, diplomático. Monterrey: Universidad Autónoma de Nuevo León, 1997.

VILLALTA VIZCARRA, Ana Elizabeth. El Derecho Internacional Privado en el sistema Interamericano. In: SEMINARIO DE AMEDI, 2012, México, DF. Anais [...]. México, D: [s. n.], 2012. p. 1-23. Disponible en: https://sociedip. files.wordpress.com/2013/12/el-derecho-internacional-privado-en-el-sistema-interamericano-ana-elizabeth-villalta-viscarra.pdf. Accedido en 10 sept. 2019.

WEHRLI, Yannik. "États latino-américains, organisms multilatéreaux et defense de la souveraineté entre Société des Nations et espace continental panaméricain (1919-1939), Tesis (doctorado inédita). - Université de Genève, Ginebra, 2016.

\section{Alexandra Pita González}

Doctora en Historia por El Colegio de México. Miembro del Sistema Nacional de Investigadores, y de la Academia Mexicana de Ciencias. Editora de la Revista de Historia de América.

\section{Dirección}

Alexandra Pita González

Universidad de Colima

Gabriela Mistral 299a

Colonia Lomas de Circunvalación 28010

Colima, Colima, México. 